INFLAMMATORY BOWEL DISEASE

\title{
Activation of nuclear factor $\kappa B$ in colonic mucosa from patients with collagenous and ulcerative colitis
}

\author{
L Andresen, V L Jørgensen, A Perner, A Hansen, J Eugen-Olsen, J Rask-Madsen
}

Gut 2005;54:503-509. doi: 10.1136/gut.2003.034165

See end of article for authors' affiliations

Correspondence to:

Professor J Rask-Madsen, Department of

Gastroenterology C-112,

Herlev Hospital, Herlev

Ringvej 75, DK-2730

Herlev, Denmark; jrm@

dadlnet.dk

Revised version received

7 June 2004

Accepted for publication

5 July 2004
Background and aims: Expression of inducible nitric oxide synthase (iNOS) is greatly upregulated in the colonic mucosa of patients with collagenous and ulcerative colitis. As the transcription factor nuclear factor $\kappa B\left(N F_{\kappa} B\right)$ is a major inducer of iNOS gene expression, we compared activation and transcriptional activity of NFKB in colonic mucosal biopsies from these patients.

Patients: Eight patients with collagenous colitis, six with relapsing ulcerative colitis, and eight with uninflamed bowel were studied.

Methods: NFKB DNA binding activity was assessed by electrophoretic mobility shift assay and inhibitor of $N F_{\kappa B}\left(I_{\kappa B}\right)$ kinase (IKK) activity by immunocomplex kinase assay. In vivo recruitment of NFKB to the iNOS promoter was determined by chromatin immunoprecipitation analysis and transcriptional activity by $N F \kappa B$ gene expression profiling arrays. Cells showing NFKB activation were identified by immunohistochemistry. Results: In collagenous and ulcerative colitis, as opposed to uninflamed bowel, IKK $\beta$ activity and strong $N F_{K B}$ DNA binding gave rise to activation of identical NFKB subunits and recruitment of transcriptionally active p65 to the iNOS promoter. In collagenous colitis, activated $N F \kappa B$ was observed only in epithelial cells while up to $10 \%$ of lamina propria macrophages showed activation in ulcerative colitis.

Conclusions: In collagenous and ulcerative colitis, colonic mucosal NFאB is activated and recruited to the iNOS promoter in vivo via an IKK $\beta$ mediated pathway. As collagenous colitis is not associated with tissue injury, these data challenge the prevailing view that activation of NFKB per se mediates tissue injury. Our results suggest that downstream inflammatory reactions leading to tissue damage originate in lamina propria immune cells, as increased $N_{K} B$ activity in collagenous colitis was localised solely in epithelial cells, but present also in macrophages in ulcerative colitis.
C ollagenous colitis is an inflammatory bowel disease of unknown aetiology characterised by chronic watery diarrhoea in the absence of mucosal injury. Endoscopic appearance is usually normal but colonic mucosal biopsies reveal infiltration of lymphocytes and plasma cells in the lamina propria, thickened subepithelial layer of collagen, and excess of intraepithelial lymphocytes. Recently, we have observed greatly increased production rates of nitric oxide (NO) into the colonic lumen of patients with collagenous colitis $^{1}$ and provided evidence for the hypothesis that the enzyme, inducible NO synthase (iNOS), is the source of excess NO production. ${ }^{2}$ As surgical exclusion of the colon by split ileostomy induces clinical and histological remission ${ }^{3}$ and re-establishment of gut continuity causes a rapid relapse, one or more unknown luminal factor(s) may be responsible for induction of iNOS at the luminal border of the colonic epithelium.

One of the major transcriptional inducers of iNOS gene expression is the transcription factor nuclear factor $\mathrm{kB}$ $(\mathrm{NFKB}) .{ }^{4}$ Signal transduction through NFKB is initiated on binding of ligands to cell membrane receptors (for example, Toll-like receptor 2 and 4, tumour necrosis factor (TNF) receptor, and interleukin (IL)-1 receptor) and intracellular recognition receptors (for example, nucleotide oligomerisation domain (NOD)- 1 and NOD-2) leading to activation of the IкB kinase (IKK) complex and subsequently phos-

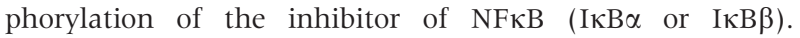
Phosphorylation targets the inhibitor to polyubiquitination and proteasomal degradation, thus activating NFKB. Active $\mathrm{NF} \kappa \mathrm{B}$ translocates into the nucleus where it binds to the promoter region of multiple genes with predominantly proinflammatory actions. In addition to stimulating expression of IL-1, TNF- $\alpha$, IL-6, IL-8, major histocompatibility complex class II, and intercellular adhesion molecule l, activated NFKB also stimulates expression of iNOS and its own inhibitor, IкB $\alpha$. Thus a single central pathway mediates activation signals from multiple bacterial and cytokine stimuli to increase production of a characteristic profile of proinflammatory molecules.

In ulcerative colitis, which is characterised by relapsing injurious inflammation of the colorectal mucosa, NFKB activation has been reported to occur both in macrophages and epithelial cells ${ }^{67}$ resulting in high expression levels of iNOS $^{8}$ and excess production of NO. ${ }^{1}$ As similarly high levels of iNOS are observed in the apparently normal colonic mucosa from patients with collagenous colitis, ${ }^{2}$ it seems a priori unlikely that upregulation of iNOS, and thus NFKB per se, should be responsible for the tissue injury observed in active ulcerative colitis. To test this hypothesis, we compared DNA binding and transcriptional activity of NFKB in colonic mucosal biopsies from patients with active collagenous colitis, active ulcerative colitis, and uninflamed bowel, in

\footnotetext{
Abbreviations: ANOVA, analysis of variance; BSA, bovine serum albumin; DTT, dithiothreitol; EDTA, ethylenediaminetetra-acetic acid; EMSA, electrophoretic mobility shift assay; EGTA, ethylene glycol-bis(2aminoethylether) tetra-acetic acid; GST, glutathione S-transferase; IKB, inhibitor of $N F \kappa B$; IKK, I $K B$ kinase; IL, interleukin; iNOS, inducible nitric oxide synthase; IP, immunoprecipitation; MOPS, 3-morpholinopropane-sulfonic acid; $N F \kappa B$, nuclear factor $\kappa B$; $N O$, nitric oxide; $N O D$, nucleotide oligomerisation domain; NP-40, nonidet $p-40$; PBS, phosphate buffered saline; PCR, polymerase chain reaction; PMSF phenylmethylsulfonyl fluoride; PNPP, p-nitrophenyl phosphate; PVDF, polyvinylidene difluoride; SDS, sodium dodecyl sulphate; SAC, Staphylococcus aureus Cowan 1; TBE, tris borate EDTA; TNF, tumour necrosis factor; WT, wild-type
} 
addition to identifying the cell types responsible for $\mathrm{NF \kappa B}$ activation in the named conditions.

\section{MATERIALS AND METHODS Patients}

Permission for the study was obtained from the regional ethics committee and all participants gave informed written consent. Patients with an established diagnosis of collagenous colitis, based on typical histopathological features, ${ }^{9}$ were included if they had experienced diarrhoea (stool volume $>300 \mathrm{ml}$ ) for at least three consecutive days during the week prior to endoscopy. All medication was discontinued at least two weeks prior to the study. Patients with relapsing ulcerative colitis were included if they had endoscopic disease activity at routine examination and had received no topical treatment or systemic corticosteroids within the past month or immunosuppressive drugs within the past three months. Oral 5-aminosalicylic acid at a daily dose of 2-4 g was allowed, if no change in medication had been made in the last two weeks prior to the investigation. Stool cultures and microscopy were performed in all patients with colitis to detect pathogens, including Clostridium difficile, and all were negative. Patients referred for endoscopy for symptoms of irritable bowel syndrome or haematochezia to exclude colorectal cancer served as controls if they had a normal colonoscopy and uninflamed mucosa at histopathological examination.

\section{Preparation of fusion proteins}

Four glutathione $S$-transferase (GST) fusion proteins were made: (a) GST-IKB $\alpha$ (1-54) WT containing the wild-type (WT) $\mathrm{N}$ terminal regulatory domain (residues 1-54) of the

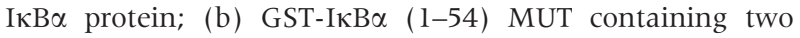
phosphorylation sites, serine 32 and 36 , replaced by alanine; (c) GST-p100 (754-900) WT containing the C terminal regulatory domain (residues 754-900) of the NFKB2 protein; and (d) GST-p100 (754-900) MUT containing two phosphorylation sites, serine 866 and 870, replaced by alanine. Constructs were made by cloning polymerase chain reaction

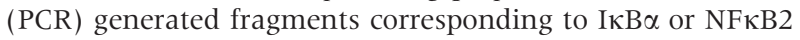
p100, respectively, into the pGEX-2T vector (Amersham Biosciences, Buckinghamshire, UK). Mutants were made by site directed mutagenesis with the Quickchange kit (Stratagene, La Jolla, California, USA) using the manufacturer's recommendations. Mutations were verified by sequencing (MWG-Biotech, Ebersberg, Germany). Fusion protein was made by transforming One Shot BL2l(DE3) cells (Invitrogen, Paisley, UK) with each construct and an overnight culture in $5 \mathrm{ml}$ of LB broth medium with $100 \mu \mathrm{g} / \mathrm{ml}$ ampicillin was performed. Next day, $1 \mathrm{ml}$ of each overnight culture was inoculated into $100 \mathrm{ml} \mathrm{LB}$ broth medium with $100 \mu \mathrm{g} / \mathrm{ml}$ ampicillin and allowed to grow to an OD600 of $0.6-0.8$, before protein expression was induced by adding isopropylthio-b-D-galactoside to a final concentration of $0.4 \mathrm{mM}$. The culture was grown for an additional two hours before cells were harvested by centrifugation. Cell pellets were resuspended in $2 \mathrm{ml}$ of ice cold lysis buffer (phosphate buffered saline (PBS) with $1 \%$ nonidet p-40 (NP-40) and protease inhibitor cocktail 1:500) and sonicated three times on ice in short 10 second bursts alternating with a 10 second resting on ice. After centrifugation of samples, the GSTfusion proteins were purified on a GST purification column (Amersham Biosciences) according to the manufacturer's recommendations.

\section{Kinase assay}

The assay was performed as described by Joseph A DiDonato. ${ }^{10}$ Briefly, $300 \mu \mathrm{g}$ of cytosol extract was precleared with protein G-Sepharose FF (Amersham Biosciences) and incubated for one hour with either $2 \mu \mathrm{g}$ anti-IKK $\alpha$ (\#556532; BD Pharmingen, San Diego, California, USA) or $2 \mu \mathrm{g}$ antiIKK $\beta$ (\#sc-7329; Santa Cruz Biotechnology, Santa Cruz, California, USA) on a rotating platform at $4^{\circ} \mathrm{C}$ followed by addition of protein G-Sepharose and incubation for an additional hour. Protein $G$ beads were then pelleted by centrifugation and washed twice in wash buffer $(20 \mathrm{mM}$ HEPES-KOH ( $\mathrm{pH} 7.6), 40 \mathrm{mM} \beta$-glycerophosphate, $20 \mathrm{mM}$ $\mathrm{NaF}, 20 \mathrm{mM}$ p-nitrophenyl phosphate (PNPP), $1 \mathrm{mM}$ dithiothreitol (DTT) $1 \mathrm{mM} \mathrm{Na} \mathrm{VO}_{4}, 0.1 \%$ NP-40, $1 \mathrm{mM}$ phenylmethylsulfonyl fluoride (PMSF), and protease inhibitor cocktail (\#P8340; Sigma, St Louis, Missouri, USA) diluted 1:500)), twice in wash buffer with $2 \mathrm{M}$ urea, twice in kinase buffer (20 mM HEPES-KOH (pH 7.6), 20 mM $\beta$-glycerophosphate, $10 \mathrm{mM}$ PNPP, $50 \mathrm{mM} \mathrm{NaCl}, 2 \mathrm{mM}$ DTT, $0.1 \mathrm{mM}$ $\mathrm{Na}_{3} \mathrm{VO}_{4}$, and protease inhibitor cocktail), and once in kinase buffer with $10 \mathrm{mM} \mathrm{MgCl} 2$. The assay was performed in $10 \mu \mathrm{l}$ kinase buffer with $\mathrm{MgCl}_{2}$ and supplemented with $5 \mu \mathrm{Ci}$ $\left[\gamma-{ }^{32} \mathrm{P}\right]$ ATP (Amersham Biosciences) and $1 \mu \mathrm{g}$ GST fusion protein at $30^{\circ} \mathrm{C}$ for one hour. The reactions were separated by electrophoresis and blotted onto a PVDF membrane. Activity was visualised on a phosphor-imager (FujiFilm, Stockholm, Sweden).

\section{Western blot analysis}

Western blotting was carried out as previously described. ${ }^{2}$ Antibodies used in this analysis were: anti $\operatorname{IKK} \beta(\mathrm{C}-20)$ from Santa Cruz Biotechnology and anti-IKK $\alpha$ from BD Pharmingen.

\section{Preparation of cytosolic and nuclear extracts}

Six fresh biopsies were gently homogenised in ice cold $500 \mu \mathrm{l}$ buffer H ( 10 mM HEPES-KOH (pH 7.9), 10 mM KCl, 0.1 mM ethylenediaminetetra-acetic acid (EDTA), $0.1 \mathrm{mM}$ ethylene glycol-bis-(2-aminoethylether) tetra-acetic acid (EGTA), $0.75 \mathrm{mM}$ spermidine, $0.15 \mathrm{mM}$ spermine, $1 \mathrm{mM}$ DTT, $1 \mathrm{mM}$ PMSF, and protease inhibitor cocktail diluted 1:500) in a Dounce homogeniser with a B-type pestle. Then, $5 \mu \mathrm{l}$ $10 \%$ NP-40 was added and the homogenate was allowed to stand for 10 minutes on ice followed by two gentle strokes with the B-type pestle. The homogenate was transferred to a microfuge tube, underlaid with $400 \mu \mathrm{l}$ buffer $\mathrm{H}$ with $30 \%$ $(\mathrm{w} / \mathrm{v})$ sucrose, and centrifuged at $1200 \mathrm{~g}$ for 10 minutes in a swing out rotor. After centrifugation, the upper (cytosolic) phase was transferred to a new tube, frozen in liquid nitrogen in small aliquots, and stored at $-80^{\circ} \mathrm{C}$ until required for analysis. The nuclear pellet was resuspended in $400 \mu \mathrm{l}$ buffer $\mathrm{N}(20$ mM HEPES-KOH (pH 7.6), 20\% (v/v) glycerol, 10\% (w/v) sucrose, $420 \mathrm{mM} \mathrm{KCl}, 5 \mathrm{mM} \mathrm{MgCl}_{2}, 0.1 \mathrm{mM}$ EDTA, $1 \mathrm{mM}$ DTT, $1 \mathrm{mM}$ PMSF, and protease inhibitor cocktail 1:500) and incubated for 45 minutes on an end over end rotor in a cold room followed by centrifugation for 30 minutes at $20000 \mathrm{~g}$. The nuclear extract was then dialysed overnight against buffer D (20 mM HEPES-KOH (pH 7.9), 20\% v/v glycerol, $0.2 \mathrm{mM}$ EDTA, $0.1 \mathrm{M} \mathrm{KCl}, 0.5 \mathrm{mM}$ PMSF, and $1 \mathrm{mM}$ DTT). The formed precipitate was removed by centrifugation and the extract was concentrated by centrifugation through an Ultrafree- 0.5 centrifugation tube (Millipore, Bedford, Massachusetts, USA) with a $5 \mathrm{~K}$ cut off membrane until the sample volume was reduced to approximately $50 \mu \mathrm{l}$. Extracts were frozen in small aliquots in liquid nitrogen and stored at $-80^{\circ} \mathrm{C}$ until required. Protein concentration was determined by the Bradford method (BioRad, Hercules, California, USA) using bovine serum albumin (BSA) as a reference.

\section{Electrophoretic mobility shift assay}

Electrophoretic mobility shift assay (EMSA) was performed by incubating $5 \mu \mathrm{g}$ nuclear extract with $1 \mu \mathrm{g}$ sonicated poly (dI:dC) (Amersham Bioscience), $1.5 \mu \mathrm{l}$ mobility shift buffer 
( $100 \mathrm{mM}$ HEPES-KOH, pH 7.9, $600 \mathrm{mM} \mathrm{KCl,} 40 \mathrm{mM} \mathrm{MgCl}$, $1 \mathrm{mM}$ EDTA, $1 \mathrm{mg} / \mathrm{ml} \mathrm{BSA}$, and $2.5 \mathrm{mM}$ DTT), $1.5 \mu \mathrm{l}$ glycerol, and water to a final volume of $14 \mu \mathrm{l}$, followed by addition of $5 \mathrm{fmol}^{32} \mathrm{P}$ labelled double stranded oligonucleotide (specific activity $15000 \mathrm{cpm} / \mathrm{fmol}$ ) corresponding to the Ig- $\kappa \mathrm{B}$ promoter (5'-AGC TTC AGA GGG GAC TTT CCG AGA GGT CGA-3'). Samples were incubated at room temperature for 30 minutes and loaded on a pre-run 5\% acrylamide gel containing $45 \mathrm{mM}$ Tris borate and $1 \mathrm{mM}$ EDTA $(0.5 \times \mathrm{TBE})$, and run for 25 minutes at $200 \mathrm{~V}$ in $0.5 \times \mathrm{TBE}$. Then the gel was fixed in $10 \%$ acetic acid/ $20 \%$ methanol/70\% water for 15 minutes, dried under vacuum on a piece of Whatman 3 MM paper (Whatman International, Kent, UK), exposed to a phosphor-imaging plate for at least 12 hours, and analysed on a phosphor-imager (FujiFilm). For supershift experiments, extracts were incubated with $2 \mu \mathrm{g}$ antibody overnight at $4^{\circ} \mathrm{C}$ prior to addition of labelled probe.

\section{Chromatin immunoprecipitation}

This method was based on a protocol from Peggy Farnham's Laboratory ${ }^{11}$ (http://genomcenter.ucdavis.edu/ farnham/farnham). Two colonic mucosal biopsies were collected in PBS with $1 \%$ formaldehyde and allowed to stand at room temperature for 15 minutes before cross linking was stopped by addition of glycine to a final concentration of $0.125 \mathrm{M}$. Then the biopsies were washed in ice cold PBS with $1 \mathrm{mM}$ PMSF and inhibitor cocktail (diluted 1:500) and transferred to a small Dounce homogeniser. Homogenisation was done with a B-type pestle and cells were swelled in lysis buffer ( 5 mM PIPES pH 8.0, $85 \mathrm{mM} \mathrm{KCl,} \mathrm{0.5 \%} \mathrm{NP40,} 1 \mathrm{mM}$ PMSF, and inhibitor cocktail) for 10-15 minutes followed by two strokes with the pestle. The nucleus was isolated by centrifugation, resuspended in nuclear lysis buffer $(50 \mathrm{mM}$ Tris-Cl pH 8.1, 10 mM EDTA, 1\% sodium dodecyl sulphate (SDS), $1 \mathrm{mM}$ PMSF, and inhibitor cocktail) and left in ice for 30 minutes. Chromatin was sheared by sonication to an average length of $1000-500 \mathrm{bp}$ and centrifuged at $15000 \mathrm{rpm}$ for 10 minutes. The chromatin solution was precleared with addition of Staphylococcus aureus Cowan 1 (SAC) for 15 minutes at $4^{\circ} \mathrm{C}$. Before use, SAC was blocked with $1 \mu \mathrm{g} / \mu \mathrm{l}$ sheared herring sperm DNA and $1 \mu \mathrm{g} / \mu \mathrm{l}$ BSA and incubated overnight at $4^{\circ} \mathrm{C}$. The precleared chromatin sample was split into two, diluted 10 times with IP dilution buffer ( $16.7 \mathrm{mM}$ Tris-Cl pH 8.0, $167 \mathrm{mM} \mathrm{NaCl}, 1.2 \mathrm{mM}$ EDTA, $1.1 \%$ Triton $\times 100$, and $0.01 \%$ SDS) and incubated overnight at $4{ }^{\circ} \mathrm{C}$ with $2 \mu \mathrm{l}$ anti-p65 (\#SA-238; Biomol, Plymouth Meeting, Pennsylvania, USA), or with no antibody, respectively. A third sample containing only IP dilution buffer and antibody was also included. The next day, antibody was precipitated by addition of SAC for one hour followed by centrifugation. The supernatant from the sample with no antibody was set aside for total input assessment. Samples were then washed twice in cold dialysis buffer ( $50 \mathrm{mM}$ Tris-Cl pH 8.0, 2 mM EDTA, and 0.2\% Sarkosyl) and five times in cold IP wash buffer ( $100 \mathrm{mM}$ Tris-Cl pH 9.0, $500 \mathrm{mM} \mathrm{LiCl}, 1 \%$ NP-40, and 1\% deoxycholic acid). Thereafter, the samples were eluted from the SAC by incubation twice in $150 \mu \mathrm{l}$ elution buffer $\left(50 \mathrm{mM} \mathrm{NaHCO}_{3}\right.$, $1 \%$ SDS) for 15 minutes. The eluates were collected into a single tube and cross linking was reversed by incubating samples with $10 \mu \mathrm{g}$ RNase A in a $0.3 \mathrm{M} \mathrm{NaCl}$ solution at $67^{\circ} \mathrm{C}$ for five hours. DNA was precipitated by addition of 2.5 volumes of ethanol and left at $-20^{\circ} \mathrm{C}$ overnight. Then, the DNA was redisolved in TE buffer $(10 \mathrm{mM}$ Tris- $\mathrm{HCl} \mathrm{pH}$ 8.0, 1 mM EDTA, pH 8.0) and treated with $30 \mu \mathrm{g}$ Proteinase $\mathrm{K}$ (Roche, Mannheim, Germany) for 90 minutes at $45^{\circ} \mathrm{C}$, followed by extraction with phenol/chloroform/isoamyl alcohol and chloroform/isoamyl alcohol, respectively. DNA was then precipitated with $0.3 \mathrm{M} \mathrm{NaCl}, 5 \mu \mathrm{g}$ glycogen, $5 \mu \mathrm{g}$ tRNA, and two volumes of ethanol overnight at $-20^{\circ} \mathrm{C}$ and redisolved the following day in $30 \mu \mathrm{l} 10 \mathrm{mM}$ Tris, $\mathrm{pH}$ 8.0. We used $1 \mu$ l per PCR reaction.

\section{Gene expression profiling}

Colonic mucosal biopsies were immediately submerged into ice cold RNAlater (Ambion, Austin, Texas, USA) and incubated at $4^{\circ} \mathrm{C}$ overnight. Total RNA was extracted using Trizol reagent (Invitrogen) and genomic DNA contamination was removed with DNA-free (Ambion). The integrity of purified RNA was assessed by running $1 \mu \mathrm{g}$ RNA on a $1 \%$ agarose gel containing $2.2 \mathrm{M}$ formaldehyde in 3morpholino-propane-sulfonic acid (MOPS) electrophoresis buffer (20 mM MOPS (pH 7.0), 2 mM Na-acetate, and $1 \mathrm{mM}$ EDTA ( $\mathrm{pH} 8.0))$. Gene expression profiling was done as described by the manufacturer using the GEArray Q Series Human NFкB Signaling Pathway Gene Array (SuperArray Bioscience Corp, www.superarray.com) and $1.5 \mu \mathrm{g}$ total RNA. Images were recorded with FujiFilm LAS-1000 equipment and quantification of spots was done using FujiFilm ImageGauge v 4.0 software. Data were normalised to the mean of all housekeeping genes provided on the array.

\section{Double labelled immunohistochemistry}

A phospho specific antibody, phospho-NFKB p65(Ser276) (\#3037; Cell Signalling Technology, Beverly, Massachusetts, USA) was employed to distinguish active from inactive NFKB. Antibodies against CD68 (a macrophage marker) and vimentin (a fibroblast marker) were purchased from DakoCytomation (Glostrup, Denmark). Parallel sections of formalin fixed and paraffin embedded tissue samples $(5 \mu \mathrm{m})$ were dewaxed in Tissue-Clear (Sakura Finetek Europe,
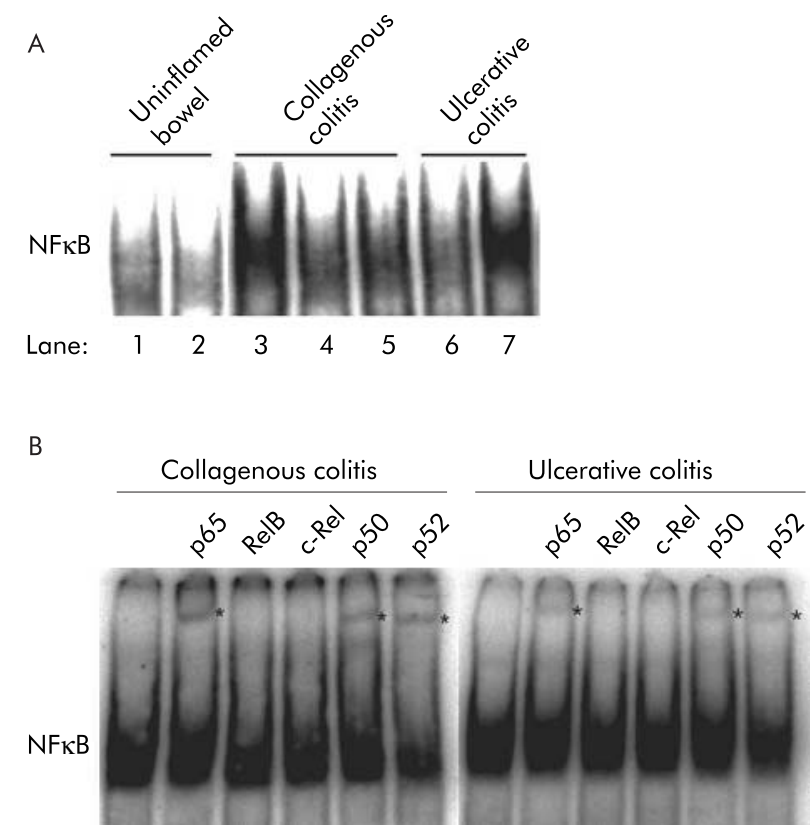

Figure 1 ( $A$ ) Nuclear factor $\kappa B(N F \kappa B)$ DNA binding activity in nuclear extracts of colonic mucosal biopsies from patients with uninflamed bowel, collagenous colitis, or ulcerative colitis. Nuclear extracts were incubated with a ${ }^{32} \mathrm{P}$ labelled $\mathrm{\kappa} B$ oligonucleotide probe and subjected to electrophoretic mobility shift assay (EMSA). Lanes 1, 2: patients with uninflamed bowel; lanes 3-5: patients with collagenous colitis; lanes 6, 7: patients with mild and severe ulcerative colitis, respectively. A representative result of two experiments is shown. (B) Nuclear extracts of colonic mucosal biopsies from patients with active ulcerative colitis or collagenous colitis were incubated with antibodies prior to EMSA analysis. An asterisk $\left({ }^{*}\right)$ denotes supershifted bands. A representative result of two experiments is shown. 


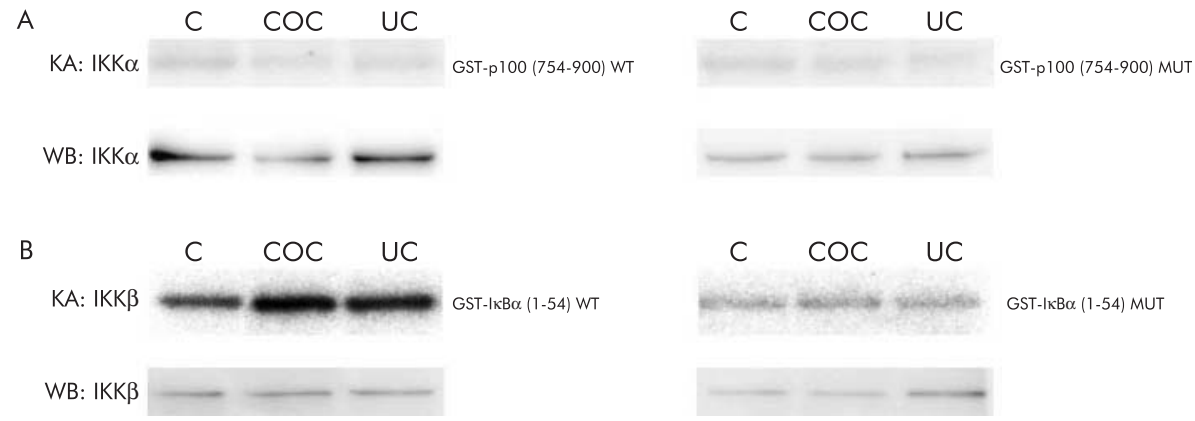

Figure 2 In vitro IKB kinase (IKK) activities in cytosolic extracts of colonic mucosal biopsies from patients with uninflamed bowel (C), active collagenous colitis (COC), or ulcerative colitis (UC). (A, B) IKK $\alpha$ and IKK $\beta$ activities determined by immune complex kinase assay (KA) using cytosolic extracts of colonic mucosal biopsies incubated with glutathione S-transferase (GST)-p100 (754-900) (A) or GST-IKB $\alpha(1-54)$ (B) substrate and radioactive ATP. The specificity of phosphorylation was determined by comparing reactions with wild-type (WT) or mutant (MUT) substrates, in which serine 866 and 870 (A) or serine 32 and 36 (B) were replaced by alanine. The reaction mixture was resolved on an acrylamide gel, transferred to a polyvinylidene difluoride membrane and subjected to phosphorimager analysis. The membrane was subsequently probed with antibody against IKK $\alpha$ or IKK $\beta$ as a loading control using western blot analysis (WB). A representative result of six assays is shown.

Zoeterwoude, the Netherlands) for 15 minutes and thoroughly hydrated through series of diluted ethanol. Sections were then subjected to an antigen retrieval step by microwave oven treatment for 15 minutes in $10 \mathrm{mM}$ Tris, $\mathrm{pH}$ 9.0, $0.5 \mathrm{mM}$ EGTA solution. Staining was performed by use of the EnVision Doublestain System (\#K1395; DakoCytomation). Substrates provided by the kit were however substituted with aminoethylcarbazole (\#A6926; Sigma; staining red) and Fast Blue BB (\#F3378; Sigma; staining blue). Anti-phosphoNFKB (Ser276) antibody was diluted 1:40, anti-CD68 1:5000, and anti-vimentin 1:400. Stained tissue was interpreted as previously described..$^{12}$ Thus red-brown nuclear cell staining was used as an index for activation induced nuclear translocation of NFкB. Concomitant intense blue-granular cytoplasmic staining was used to identify macrophages (CD68 positive cells) or fibroblasts (vimentin positive cells). The stained tissue was scored in a blinded manner by two investigators (AH and LA) using a double headed microscope, as described by Geddert and colleagues. ${ }^{13}$ The following criteria were agreed upon before analysis of NFKB staining: 0 , no nuclear staining; + , nuclear staining in $1-10 \%$ of the cell type under examination; ++ , nuclear staining in $11-25 \%$ of

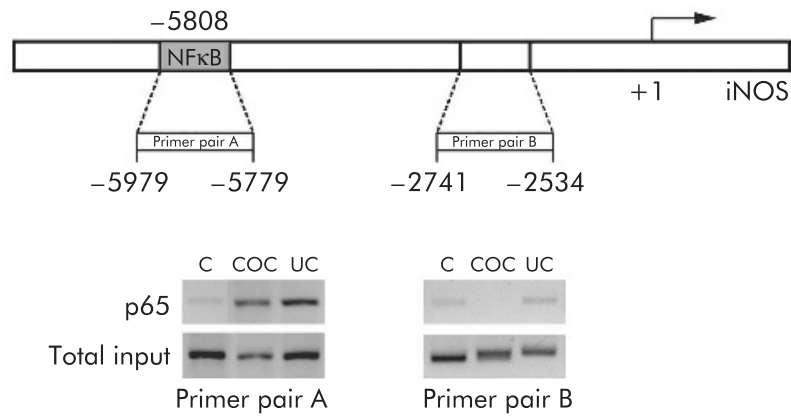

Figure 3 Chromatin immunoprecipitation assay of $\mathrm{p} 65$ binding to a nuclear factor $\kappa B(N F \kappa B)$ regulatory region within the inducible nitric oxide synthase (iNOS) promoter in nuclear extracts of colonic mucosal biopsies from patients with uninflamed bowel $(C ; n=2)$, collagenous colitis (COC, $n=2)$, or active ulcerative colitis $(U C, n=2)$. Soluble chromatin was prepared from formaldehyde cross linked sonicated biopsies. Specific antibody against p65 was used to precipitate protein bound DNA fragments which were subsequently amplified by polymerase chain reaction using primers flanking an NFKB regulatory region $(-5979$ to -5779 ; primer pair $\mathrm{A})$ or a non-regulatory region $(-2741$ to -2534 ; primer pair B). Total input refers to amplification of $1 \%$ of the total amount of DNA prior to immunoprecipitation. the cell type under examination; +++ , nuclear staining in over $25 \%$ of the cell type under examination.

\section{Statistics}

Categorical data were analysed by $\chi^{2}$ test and continuous data by one way analysis of variance (ANOVA) followed by Tukey's multiple comparison test. Prior to ANOVA, Bartlett's test was performed to test for equal variances. If positive, data were log transformed and if unequal variances persisted the final analysis was done by Kruskal-Wallis test. A p value of $<0.05$ (two tailed) was considered significant.

\section{RESULTS}

DNA binding activity of NF $\kappa$ B is enhanced in collagenous and ulcerative colitis

DNA binding activity in nuclear extracts of colonic mucosal biopsies from patients with uninflamed bowel showed weak binding activity (fig $1 \mathrm{~A}$, lanes 1 and 2) while strong binding activity was observed in all patients with collagenous colitis (fig 1A, lanes 3-5) and relapsing ulcerative colitis (fig 1A, lanes 6 and 7).

\section{Patterns of activated NFкB subunits are similar in collagenous and ulcerative colitis}

Supershift analysis using antibodies specific for $\mathrm{NF \kappa B}$ revealed activation of a similar subset of NFKB subunits in collagenous and ulcerative colitis, including p65, p50, and p52 (fig 1B).

IKK $\beta$ is activated both in collagenous and ulcerative colitis in the absence of IKKa activation

As illustrated in fig 2A, the intensity of bands in wildtype substrates and mutated substrates, respectively, showed no specific IKK $\alpha$ activity. In contrast, IKK $\beta$ was equally activated in patients with collagenous colitis and relapsing ulcerative colitis $(\mathrm{p}<0.05$ compared with uninflamed bowel; fig $2 \mathrm{~B}$ ).

\section{NFKB binds to the iNOS promoter in vivo in collagenous and ulcerative colitis}

In biopsies from all patients with collagenous and ulcerative colitis, chromatin immunoprecipitation analysis showed that $\mathrm{NF} \kappa \mathrm{B}$ p65 was recruited to an $\mathrm{NF \kappa B}$ regulatory element 5808 bp upstream of the transcriptional start site of the iNOS gene $^{4}$ but not to an irrelevant region (fig 3). No recruitment was observed in uninflamed bowel. 
Table 1 Multiple mRNA expression of nuclear factor $\kappa B$ dependent genes in biopsies of colonic mucosa from patients with collagenous colitis, active ulcerative colitis, or uninflamed bowel

\begin{tabular}{|c|c|c|c|c|c|c|}
\hline \multirow[b]{2}{*}{ Gene name } & \multicolumn{2}{|c|}{ Uninflamed bowel $(n=7)$} & \multicolumn{2}{|c|}{ Collagenous colitis $(n=8)$} & \multicolumn{2}{|c|}{ Ulcerative colitis ( $n=6)$} \\
\hline & Median & Range & Median & Range & Median & Range \\
\hline iNOS & 5 & $(1-11)$ & $24.5^{\star}$ & $(11-115)$ & $54.5^{*}$ & $(31-258)$ \\
\hline Complement factor B & 26 & $(23-112)$ & $91.5^{*}$ & $(62-145)$ & $197.5^{*} \dagger$ & $(102-589)$ \\
\hline IL-1 $\alpha$ & 8 & $(2-18)$ & $19^{*}$ & $(11-35)$ & $19^{*}$ & $(9-48)$ \\
\hline IFN regulating factor 1 & 42 & $(29-178)$ & $111.5^{*}$ & $(74-170)$ & 71 & $(57-188)$ \\
\hline IFN- $\beta$ & 5 & $(1-11)$ & $12.5^{\star}$ & $(4-26)$ & 9 & $(7-51)$ \\
\hline IL-1 receptor associated kinase 2 & 6 & $(4-51)$ & $4^{*}$ & $(1-9)$ & $11.5 \dagger$ & $(4-16)$ \\
\hline Serum amyloid Al & 14 & $(6-23)$ & 23.5 & $(5-104)$ & $134.5^{*} \dagger$ & $(68-1038)$ \\
\hline Complement $\mathrm{C} 3$ precursor & 48 & $(24-196)$ & 74 & $(20-251)$ & $225.5^{*}$ & $(58-751)$ \\
\hline IL-8 & 6 & $(2-12)$ & 14.5 & $(5-288)$ & $26^{*}$ & $(14-150)$ \\
\hline Toll-like receptor 5 & 5 & $(3-20)$ & 8 & $(6-12)$ & $15^{*} \dagger$ & $(14-44)$ \\
\hline Angiotensinogen & 10 & $(6-18)$ & 14 & $(8-28)$ & $24.5^{*}$ & $(9-65)$ \\
\hline IL-1 receptor type 1 & 49 & $(26-51)$ & 43.5 & $(25-67)$ & $69^{*} \dagger$ & $(38-115)$ \\
\hline I $\mathrm{KB}$ kinase alpha & 48 & $(36-55)$ & 36 & $(23-59)$ & $29.5^{*}$ & $(14-42)$ \\
\hline
\end{tabular}

iNOS, inducible nitric oxide synthase; IL, interleukin; IFN, interferon; IKB, inhibitor of nuclear factor $\kappa B$.

Expression was analysed by a microarray system and quantified by densitometry.

Data were normalised by dividing individual densitometric values with the mean value of all housekeeping genes provided with the array. The table shows mRNA expression from normalised data for each gene.

$\mathrm{p}<0.05$ by one way ANOVA or Kruskal-Wallis test (see statistics) compared with *uninflamed bowel or tcollagenous colitis.

\section{Transcriptional activity of NF $\kappa B$ occurs both in} collagenous and ulcerative colitis

The transcriptional status of 96 selected NFKB dependent genes was assessed using an mRNA expression profiling array which showed statistically significant differences in mRNA expression between biopsies from patients with collagenous and ulcerative colitis compared with patients with uninflamed bowel. As illustrated in table 1, six genes were significantly upregulated or downregulated in collagenous colitis while 10 genes were upregulated or downregulated in ulcerative colitis compared with uninflamed bowel. Three of these genes (iNOS, complement factor B, and IL- $1 \alpha$ ) were upregulated in both groups of colitis patients, as illustrated in fig 4 using iNOS as an example.

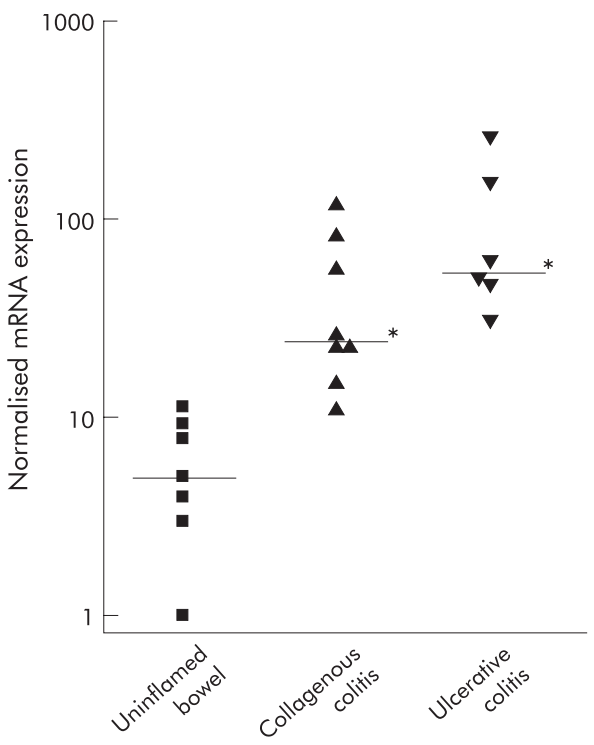

Figure 4 Expression of inducible nitric oxide synthase (iNOS) mRNA in biopsies from colonic mucosa of patients with uninflamed bowel, collagenous colitis, or active ulcerative colitis determined by a microarray system and quantified by densitometry. Data were normalised by dividing individual densitometric values with the mean value of all housekeeping genes provided with the array. In the scatterplot, the logarithmic $y$ axis denotes normalised iNOS mRNA expression, with group medians displayed as horizontal lines. ${ }^{*} p<0.05$ by one way ANOVA and Tukey's test compared with uninflamed bowel.
NFkB translocation occurs both in collagenous and ulcerative colitis but is limited to the epithelium in collagenous colitis

In biopsies from uninflamed bowel, NFKB staining (red) was negative $(0)$ or showed weak but distinct staining in less than $10 \%$ of epithelial cells (+) (fig 5A, B; table 2). No stromal cells
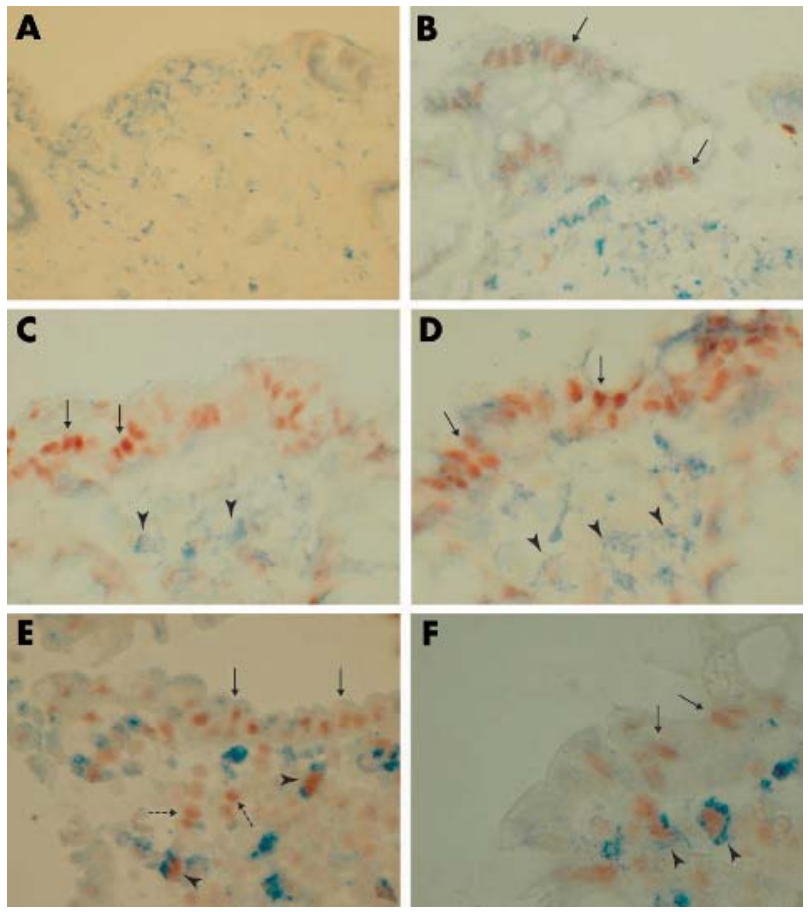

Figure 5 Double immunohistochemical detection of activated nuclear factor $\kappa B$ (NFKB) and cellular markers for macrophages (CD68) in paraffin embedded formalin fixed biopsies from patients with uninflamed bowel $(A, B)$, collagenous colitis (C, D), or ulcerative colitis $(E, F)$. Negative $N F_{K B} B$ staining $(A)$ or weak but distinct focal staining of epithelial cells ( $B$; arrows; red staining) was seen in uninflamed bowel. In collagenous colitis, $N F K B$ nuclear staining was predominantly seen in the epithelium (C, D; arrows) while CD68 positive macrophages (C, D; arrowheads; blue staining) and CD68 negative stromal cells were left unstained. In ulcerative colitis, epithelial cells (E, F; arrows), CD68 positive macrophages (E, $F$; arrowheads), and $C D 68$ negative stromal cells $\left(E_{;}\right.$broken arrows) showed intense nuclear expression of $N_{F} B$. Magnification $\times 100(\mathrm{~A}-\mathrm{E})$ and $\times 150(\mathrm{~F})$. 
Table 2 Immunohistochemical staining: scoring of nuclear factor $\kappa B$ staining according to cell type

\begin{tabular}{llll}
\hline & $\begin{array}{l}\text { Macrophages } \\
\text { (CD68 positive }\end{array}$ & $\begin{array}{l}\text { Fibroblasts } \\
\text { (vimentin } \\
\text { positive cells) }\end{array}$ \\
Material & Epithelial cells & cells) & 0 \\
\hline $\begin{array}{l}\text { Uninflamed bowel } \\
\text { Collagenous colitis ++ }\end{array}$ & 0 & 0 \\
\multicolumn{2}{l}{ Ulcerative colitis ++ } & 0 & 0 \\
\hline
\end{tabular}

Percentage of stained cells was scored as follows: 0 , no nuclear staining; + , nuclear staining in $1-10 \%$ of the cell type under examination; ++ , nuclear staining in $11-25 \%$ of the cell type under examination; +++, nuclear staining in more than $25 \%$ of the cell type examined. In uninflamed bowel, weak but distinct and focal staining was observed in epithelial cells $(0 /+)$. In collagenous colitis, only sporadic $(<1 \%)$ CD68 positive cells were seen with nuclear factor $\kappa B$ staining, with an overal score of zero (0).

showed positive NFKB staining. In biopsies from patients with collagenous colitis, diffuse NFKB staining was observed in superficial epithelial cells $(+++)$ while no, or sporadic $(<1 \%)$, macrophages (blue) showed staining (0) (fig 5C, D; table 2). In biopsies from patients with ulcerative colitis, $\mathrm{NF \kappa B}$ staining was observed both in epithelial cells $(++)$, macrophages (+), and CD68 negative stromal cells (+) (fig 5E, F; table 2). Fibroblasts (vimentin positive stromal cells) were negatively stained for $\mathrm{NF \kappa B}$ activation (0) in uninflamed bowel, collagenous colitis, and ulcerative colitis (table 2).

\section{DISCUSSION}

$\mathrm{NF \kappa B}$ activation in the colonic mucosa from patients with ulcerative colitis has previously been reported. ${ }^{67}$ The results of the present study demonstrate that NFKB is activated both in collagenous and ulcerative colitis compared with uninflamed bowel, as judged by EMSA, chromatin immunoprecipitation, and immunohistochemistry. The results of IкB kinase assays revealed that IKK $\beta$, but not IKK $\alpha$, was activated, while gene expression profiling showed markedly increased expression of iNOS and several other NFKB dependent genes. We could not demonstrate any differences between collagenous and ulcerative colitis as regards IKK

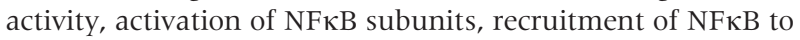
the iNOS promoter, or activation of NFKB in epithelial cells. In contrast, macrophages with activated NFKB were observed only in colonic mucosa from patients with ulcerative colitis.

Supershift analysis showed DNA binding activity of three different NFKB subunits both in collagenous and ulcerative colitis-namely, p65, NFкB1 p50, and NFкB2 p52. The presence of p65 and p50 accords with our findings of IKK $\beta$ activity in both inflammatory conditions whereas the presence of NFKB2 p52 would imply activity of IKK $\alpha$ also. ${ }^{14-16}$ Although IKK $\alpha$ was present in the mucosa, as judged by immunoblotting, there was no detectable activity in our extracts (fig 2A). Recently, it was reported that IKK $\alpha$ translocates into the nucleus on activation and phosphorylates histone $\mathrm{H} 3$ at serine 10, which is a requirement for induction of immediate-early genes. ${ }^{17}{ }^{18}$ If only a small fraction of active IKK $\alpha$ is present in the cytosolic compartment, the observed discrepancy might be explained by the absence of nuclear proteins in our IKK assays, which were performed on cytosolic extracts. Experiments on whole cell extracts should therefore be performed to clarify this issue.

Colonic mucosal biopsies consist of a variety of cell types, including epithelial cells and immune cells. Although iNOS is localised primarily to the epithelium in collagenous colitis, ${ }^{2}$ the observed NFKB DNA binding activity is not necessarily associated with iNOS expression. Thus NFKB might be active in one cell type while another cell type is the source of iNOS upregulation. At any rate, our demonstration of NFאB p65 binding to the iNOS promoter in vivo indicates that NFKB is the transcriptional activator of iNOS in the epithelium of patients with collagenous colitis.

The observation of NFאB binding to DNA is insufficient for demonstration of transcriptional activity. Numerous layers of control mechanisms, such as phosphorylation and acetylation of p65 and histones, ${ }^{17}{ }^{19-22}$ determine the transcriptional

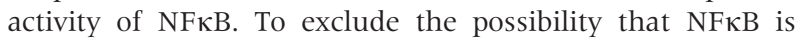
transcriptionally silent in collagenous colitis, we performed gene expression profiling on a subset of NFкB dependent genes, including iNOS, using a microarray system. Of 96 genes tested, only a few were significantly upregulated in patients with colitis but minor differences in expression pattern between collagenous and ulcerative colitis were observed, most likely reflecting the fact that $\mathrm{NF \kappa B}$ was activated in different cell types. As the genes upregulated are $\mathrm{NF \kappa B}$ dependent genes, it seems likely that NFKB is indeed transcriptionally active both in collagenous and ulcerative colitis.

As demonstration of in vivo p65 binding to the iNOS promoter in biopsy specimens from collagenous colitis provides no direct evidence of the cell types involved, we used double labelled immunohistochemical detection of activated NFKB and cellular markers for macrophages and fibroblasts (fig 5, table 2). These data showed activation of $\mathrm{NFKB}$ both in collagenous and ulcerative colitis compared with uninflamed bowel. In collagenous colitis, NFKB activation was located in epithelial cells. In contrast, activation of $\mathrm{NF} \kappa \mathrm{B}$ in ulcerative colitis was demonstrated both in macrophages and CD68 negative stromal cells, which were not fibroblasts, in addition to epithelial cells. This discrepancy suggests that activation of NFKB in epithelial cells does not lead to mucosal damage in itself. Instead, activation of NFKB in macrophages may be a prerequisite of injury in colonic inflammation. Clearly, further studies are needed to draw safe conclusions.

In summary, our results demonstrate activation of $\mathrm{NF \kappa B}$ via an IKK $\beta$ mediated pathway, recruitment of $\mathrm{NF \kappa B}$ to the iNOS promoter in vivo, and expression of NFKB dependent genes in colonic mucosal biopsies from patients with collagenous and ulcerative colitis. In collagenous colitis, activated NFKB was observed only in epithelial cells while lamina propria macrophages showed activated $\mathrm{NF \kappa B}$ in ulcerative colitis. As collagenous colitis is never associated with tissue injury, our findings challenge the prevailing view that activation of NFאB per se mediates mucosal damage in colonic inflammation. Instead, the downstream inflammatory reactions are more likely to be determined by the cellular origin of NFKB activation.

\section{ACKNOWLEDGEMENTS}

We wish to thank Anne Hallander for excellent technical assistance and Toyota Fonden Danmark for sponsoring the FujiFilm phosphorimager and the FujiFilm LAS-1000 equipment.

\section{Authors' affiliations}

L Andresen, V L Jørgensen, A Perner, J Rask-Madsen, Department of Gastroenterology, Herlev Hospital, University of Copenhagen, Denmark A Hansen, Department of Pathology, Herlev Hospital, University of Copenhagen, Denmark

J Eugen-Olsen, Clinical Research Unit, Hvidovre Hospital, University of Copenhagen, Denmark

Conflict of interest: None declared.

\section{REFERENCES}

1 Perner A, Nordgaard I, Matzen $\mathrm{P}$, et al. Colonic production of nitric oxide gas in ulcerative colitis, collagenous colitis and uninflamed bowel. Scand J Gastroenterol 2002;37:183-8. 
2 Perner A, Andresen L, Normark M, et al. Expression of nitric oxide synthases and effects of L-arginine and L-NMMA on nitric oxide production and fluid transport in collagenous colitis. Gut 2001;49:387-94.

3 Järnerot G, Tysk C, Bohr J, et al. Collagenous colitis and fecal stream diversion. Gastroenterology 1995; 109:449-55.

4 Taylor BS, de Vera ME, Ganster RW, et al. Multiple NF-kappaB enhancer elements regulate cytokine induction of the human inducible nitric oxide synthase gene. J Biol Chem 1998;273:15148-56.

5 Taylor BS, Shao L, Gambotto A, et al. Inhibition of cytokine-induced nitric oxide synthase expression by gene transfer of adenoviral I kappa B alpha. Surgery 1999; 126:142-7.

6 Rogler G, Brand K, Vogl D, et al. Nuclear factor kappaB is activated in macrophages and epithelial cells of inflamed intestinal mucosa. Gastroenterology 1998;115:357-69.

7 Schreiber S, Nikolaus S, Hampe J. Activation of nuclear factor kappa B in inflammatory bowel disease. Gut 1998;42:477-84.

8 Singer II, Kawka DW, Scott S, et al. Expression of inducible nitric oxide synthase and nitrotyrosine in colonic epithelium in inflammatory bowel disease. Gastroenterology 1996;111:871-85.

9 Lindström CG. 'Collagenous colitis' with watery diarrhoea-a new entity? Pathol Eur 1976;11:87-9.

10 DiDonato JA. Assaying for I kappa B kinase activity. Methods Enzymol 2000;322:393-400.

11 Boyd KE, Wells J, Gutman J, et al. c-Myc target gene specificity is determined by a post-DNA binding mechanism. Proc Natl Acad Sci U S A 1998;95:13887-92.

12 Kirkegaard T, Hansen A, Bruun E, et al. Expression and localisation of matrix metalloproteinases and their natural inhibitors in fistulae of patients with Crohn's disease. Gut 2004;53:701-9.
13 Geddert H, Heep HJ, Gabbert HE, et al. Expression of cyclin B1 in the metaplasia-dysplasia-carcinoma sequence of Barrett esophagus. Cancer 2002; $94: 212-18$

14 Senftleben U, Cao Y, Xiao G, et al. Activation by IKKalpha of a second, evolutionary conserved, NF-kappa B signaling pathway. Science 2001;293:1495-9

15 Dejardin E, Droin NM, Delhase $M$, et al. The lymphotoxin-beta receptor induces different patterns of gene expression via two NF-kappaB pathways. Immunity 2002;17:525-35.

16 Müller JR, Siebenlist U. Lymphotoxin beta receptor induces sequential activation of distinct NF-kappa B factors via separate signaling pathways. J Biol Chem 2003;278:12006.

17 Yamamoto Y, Verma UN, Prajapati S, et al. Histone H3 phosphorylation by IKK-alpha is critical for cytokine-induced gene expression. Nature 2003:423:655-9.

18 Anest V, Hanson JL, Cogswell PC, et al. A nucleosomal function for lkappaB kinase-alpha in NF-kappa B-dependent gene expression. Nature 2003;423:659-63.

19 Zhong H, May MJ, Jimi E, et al. The phosphorylation status of nuclear NFkappa $\mathrm{B}$ determines its association with $\mathrm{CBP} / \mathrm{p} 300$ or HDAC-1. Mol Cell 2002;9:625-36.

20 Chen L, Fischle W, Verdin E, et al. Duration of nuclear NF-kappaB action regulated by reversible acetylation. Science 2001;293:1653-7.

21 Chen L, Mu Y, Greene WC. Acetylation of RelA at discrete sites regulates distinct nuclear functions of NF- $\mathrm{KB}$. EMBO J 2002;21:6539-48.

22 Kiernan R, Bres V, Ng RWM, et al. Post-activation turn-off of NF-kappa Bdependent transcription is regulated by acetylation of p65. J Biol Chem 2003;278:2758-66.

\section{EDITOR'S QUIZ: GI SNAPSHOT}

\section{Answer}

From question on page 468

Figure 1 reveals a chronic, giant, high lesser curve ulcer with clots, and a rosette-like mucosal island. This gastrocolic fistula "stoma" was intubated at initial gastroscopy (fig 2A, 2B). Biopsy excluded malignancy. Figure 1B shows the ulcer but the fistula is incompletely visualised.

The patient was given acid suppression and nasojejunal feeding, prior to limited resectional surgery. Histology revealed no malignancy. He was discharged on day 7 and remains well three months later.

Gastrocolic fistula is an unusual complication of peptic ulceration. It must be suspected, especially in young females on ulcerogenic agents, with halitosis, feculent vomiting, postprandial diarrhoea, with or without dyspepsia or weight loss. The ulcer is usually situated on the greater curve. We believe postprandial diarrhoea was absent in this case because of its location on the lesser curve.

Contrast enema demonstrates the fistula in nearly all cases and endoscopy can be reserved for biopsy to exclude malignancy.

To our knowledge, a fistula tract permitting gastroscopic intubation of the colon has not been described previously or documented by endoscopic images.

doi: $10.1136 /$ gut.2004.048579
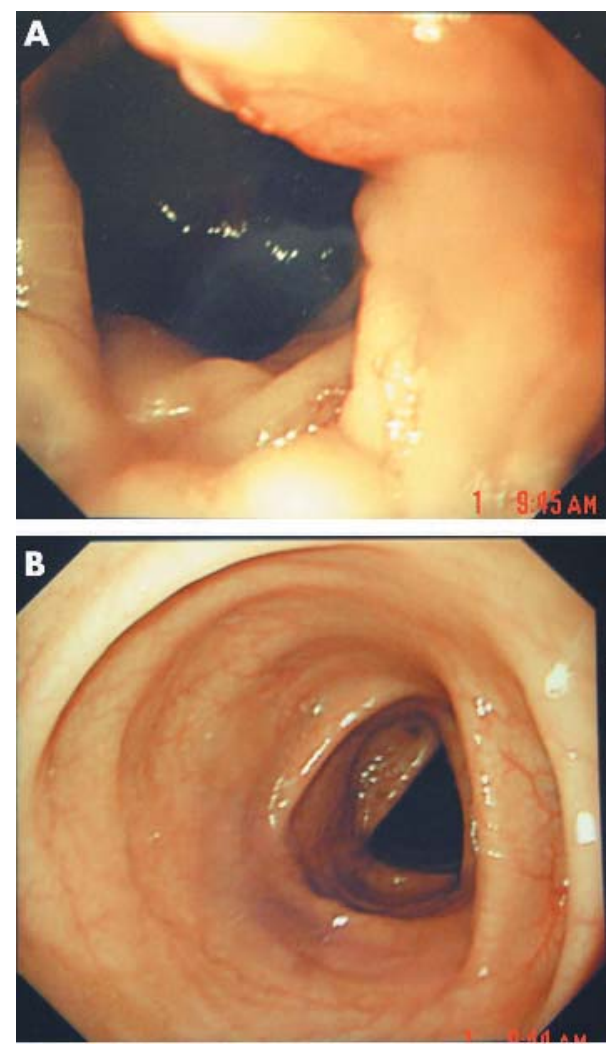

Figure 2 Intubated of the gastrocolic fistula "stoma" at initial gastroscopy. 